\title{
REFLEXÕES SOBRE A EDUCAÇÃO ESCOLAR HUNI KUĨ: PASSADO, PRESENTE E FUTURO
}

\section{Joaquim Mana \\ Norberto Sales \\ José Benedito Ferreira \\ Gilson de Lima}

Entrevista por:

Rafael Castro de Souza*

Entre os dias 25 de novembro e 10 de dezembro de 2016, aconteceu na Aldeia Água Viva - Terra Indígena Praia do Carapanã (Acre) - o Curso de Hãtxa Kũ̃. A iniciativa encabeçada pelo Prof. Dr. Joaquim Mana reuniu 56 professores Huni Kuĩ (de um total de 68 participantes) de quatro diferentes regiões do estado para debater e planejar a política pedagógica da educação escolar nas aldeias, além de revisar, ampliar e criar materiais didáticos diferenciados para o ensino da língua Hãtxa Kuĩ, especialmente em sua forma escrita. Apresentamos aqui os depoimentos de quatro professores, dentre eles, do próprio Joaquim Mana, que refletem sobre a iniciativa realizada e sobre o passado, presente e expectativas para o futuro da educação escolar Huni Kuĩ.

Os Huni Kuin, historicamente conhecidos por Kaxinawá, são aproximadamente 12.000 pessoas e vivem na divisa do Brasi
* rafaelchinaski@gmail.com

Mestrando no Programa de Pós-Graduação em Estudos Literários da Faculdade de Letras da UFMG com o trabalho intitulado $A$ vida
sensível do mito na literatura Huni Kuĩ.

com Peru, ${ }^{2}$ região de floresta amazônica. No estado do Acre, eles estão distribuídos em doze terras indígenas, com um área aproximada de 653 mil hectares, nos rios Purus, Envira, Murú, Humaitá, Tarauacá, Jordão e Breu. Eles compartilham terras com os Ashaninka, Shanenawa, Madijá e povos “isolados”.

A língua falada por eles faz parte da família linguística Pano e é chamada de Hãtxa Kuin, o que poderia ser traduzido como "conversa verdadeira" ou "língua verdadeira". As línguas Pano são faladas desde o leste peruano até o oeste amazônico, passando também pelo noroeste da Bolívia. Além do hãtxa kuin, dos Huni Kuin, estão dentre elas a língua dos Katukina, Matís, Marubo, Matses, Poyanáwa, Yamináwa, Yawanáwa, Nukini, Korubo e dos Kaxarari.
Os dados são retirados do site do Isa - Instituto Socioambiental.

. Joaquim Maná Huni Kuin sugeriu a possibilidade da palavra hatxa ser traduzida como conversa. 
PROF. DR. JOAOUIM MANA KAXINAWA, AUTOR DA TESE DE DOUTORADO UMA GRAMÁTICA DA LINGGA HÃTXA KUĨ E PRINCIPAL ARTICULADOR DAS POLÍTICAS PEDAGÓGICAS DA EDUCAÇ̃̃O ESCOLAR HUNI KUĨ, EXPLICA A INICIATIVA DO “CURSO DE HÃTXA KUĨ" E FALA SOBRE A SITUAÇÃO DA LÍNGUA NAS ALDEIAS E SOBRE A PRODUÇÃO DE MATERIAIS DIDATICOS.

O curso que está acontecendo foi uma iniciativa dos Huni Kuĩ, dentro da experiência que a gente ia convivendo com a questão da escrita, da leitura, da pesquisa. Hoje está sendo realizado praticamente um encontro específico, um ensino

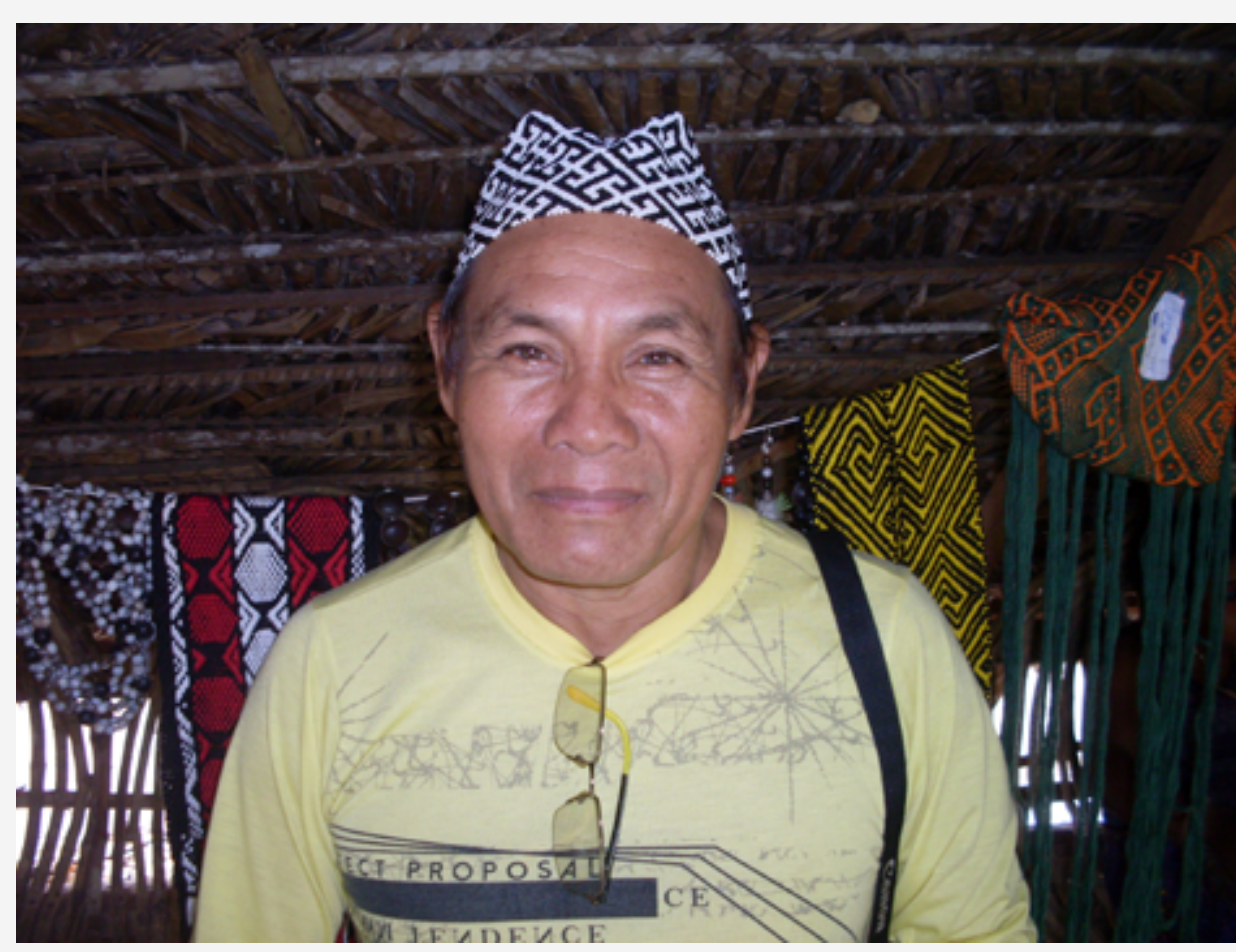

JOAOUIM MANA específico da escrita, da leitura, pensando na situação das escolas, que hoje consideramos um espaço importante para a gente construir ou reconstruir as nossas histórias que não pudemos registrar antes da chegada da escrita. Tudo isso se deu quando da pesquisa que eu estava fazendo sobre linguística. Quando terminei meu mestrado em 2011 eu voltei para mostrar o que eu tinha feito, o resultado da revisão ortográfica, e aí a gente foi pensando em dar continuidade a esse encontro. Em 2012 voltamos a fazer isso, quando se deu a ideia de fazer o primeiro material, um material de alfabetização. Até então a gente tinha uma escrita, mas nada definido, e aí a gente começou a definir a ortografia Huni Kuĩ. E nessa mesma data a gente ficou se perguntando: como a gente pode trabalhar todo esse conhecimento na escola, e ouvir mais pessoas de outras regiões? Aí todo mundo ficou comentando: a gente precisa se encontrar, porque cada um traz uma experiência e dentro dessa experiência a gente define como a gente quer continuar se encontrando e as áreas de ensino que queremos trabalhar. Aí se deu essa ideia de a gente se encontrar. Nesse encontro, nas retrospectivas que fizemos, nós chegamos a uma conclusão: antes a gente estava aprendendo. Hoje, com praticamente 50 Huni Kuĩ formados em diversas áreas, mesmo com a formação que tivemos, que não foi uma formação específica, nós podemos adaptar a formação que temos dentro do conhecimento do nosso povo, 
tanto da escrita, da leitura, da pesquisa e da publicação. E aí a gente foi identificando outras situações. O domínio que temos hoje não é suficiente. A gente começou a fazer vários questionamentos dizendo: o que nós somos agora? Estamos fortalecendo, estamos enfraquecendo? A partir de várias falas e situações das terras que temos - onde un falam bem, outros mais ou menos, outros escrevem bem, outros nada - nós chegamos à conclusão de que uma cultura está engolindo a outra cultura. Foi um desenho que fizeram, em que duas cobras se engolem. A que está engolindo seria a cultura de fora, a língua portuguesa. A que está sendo engolida é a cultura e língua Huni Kuĩ. Aí os meninos apresentaram esse desenho. Na definição do ensino, da língua, da pesquisa e da publicação, tudo em Hãtxa Kuĩ, chegamos à conclusão que nenhuma das duas cobras podem se engolir. Elas devem ter a mesma competência, o mesmo valor. Os dois pra nós é interessante aprender, ensinar, dominar. Hoje a gente continua discutindo a melhor forma de ensinar. Agora mesmo eu estava distribuindo as letras do alfabeto para ser produzido um outro material, um terceiro material que seria o ensino do Hãtxa Kuĩ na escola. Esse material tem que trazer algumas histórias que façam a gente refletir, que façam os alunos pensarem no que realmente nós queremos aprender, ensinar e continuar pesquisando. É uma situação muito problemática, e tudo isso porque foi identificado entre nós mesmos, fazendo um mapa linguístico das 33 comunidades presentes nesse curso, que 21 comunidades, 21 aldeias estão numa situação complicada. Só os mais velhos sabem o Hãtxa Kuĩ, o dominam, sabem as histórias, sabem das práticas culturais mas não as praticam porque não tem ninguém mais incentivando. E 12 seriam as outras comunidades onde está mais protegido. As práticas são só em Hãtxa Kuĩ. Aí eu quis que a gente refletisse. Temos que trabalhar nessas 33 comunidades aqui presentes no curso, em fortalecer, incentivar mais a escrita e a oralidade. Eu percebo que se todos os professores que estão aqui presentes levarem isso a sério, nós teremos um cenário muito interessante, muito positivo nos próximos anos. A gente vai ter o domínio da língua portuguesa, mas também teremos o domínio da língua Hãtxa Kuĩ, que é oral e escrita. Os materiais que a gente quer publicar, eu estava comentando com os professores, nós só temos alguns trechos de histórias. Nem todas as histórias estão completas. Quer dizer que aqueles que sabiam, que dominavam, eram os velhos que faleceram. Hoje temos alguns trechos das histórias, mas é interessante a gente publicar essas histórias, para a nova geração pesquisar, ler, refletir. Então, é uma situação bem nova esse mundo da escrita, que imagino que possa dar certo. 
4. "Tempo do cativeiro" é o nome regionalmente usado para designar o período em que povos indígenas - dentre eles, os Huni Kuĩ - eram força de trabalho dos patrões seringalistas, em uma situação muito próxima à escravidão.
NORBERTO SALES KAXINAWA (TENE TXANA SAPA), PROFESSOR DA ALDEIA FLOR DA MATA E COORDENADOR PEDAGOGICO DO MUNICÍPIO DE JORDÃO/AC, CONTA UM POUCO DO PASSADO DA EDUCAÇÃO ESCOLAR HUNI KUĨ A PARTIR DE SUA PRÓPRIA EXPERIÊNCIA DE FORMAÇÃO.

Eu quero contar um pouco sobre a história, a história da educação, que é onde começamos a educação escolar indígena do nosso povo Huni Kuĩ. Antigamente, no final do cativeiro $^{4}$, não existia escola. Dizem que tinha uma parente que saiu da aldeia, foi pra cidade, aprendeu a estudar, até a quarta

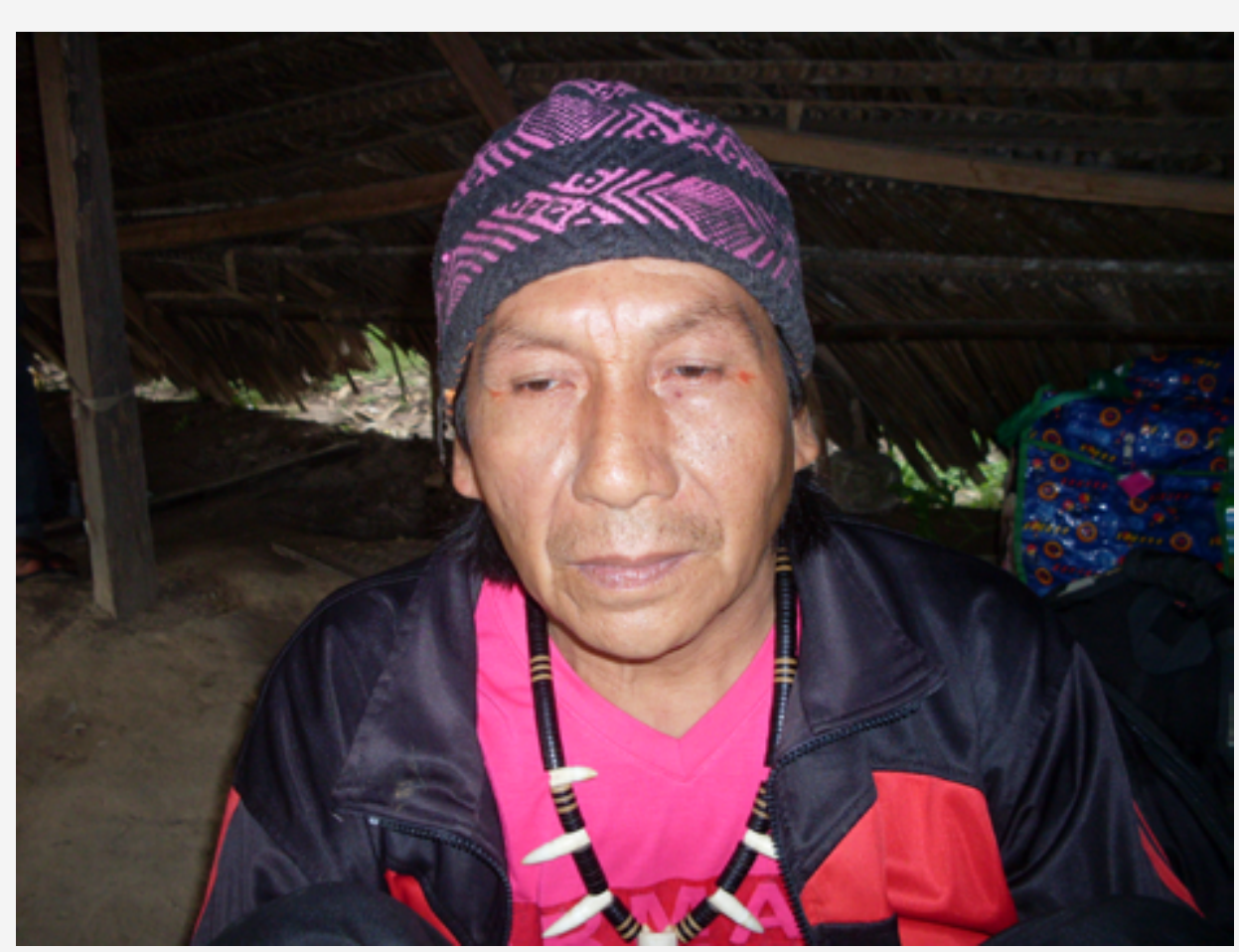

NORBERTO SALES série, por aí. Dizem que ela voltou pra aldeia, acho que mais ou menos em 1940, para repassar esse conhecimento que aprendeu quando passou na cidade, em Tarauacá, me parece. Daí se casou com um parente e começou a ensinar o que aprendeu para o cunhado, o primo, aqueles parentes próximos. E começou a ensinar a letra, o alfabeto, as palavras, alguma coisa. Meu pai aprendeu com um parente, também, mas eles não tinham o material, lápis, caneta, cadernos. Da que naquele tempo, quando eu era pequeno, eu vi que meu pai não sabia escrever. Ele escrevia o nome e sabia ler um pouco as frases. Eu aprendi com ele as letras do alfabeto. Quando fiz dez anos meu pai faleceu, aí eu aprendi com o meu tio, a responsabilidade caiu no meu tio. Daí, em 1975, parece, tinha um professor também Huni Kuĩ, que não era professor, né, mas era um seringueiro que foi viajar para a cidade de Tarauacá e conseguiu uns materiais, uma cartilha do Mobral (Movimento Brasileiro de Alfabetização). Ele chegou e matriculou os parentes, passaram sete meses, parece. Eu não me matriculei daquele tempo. Passou um tempo e chegaram dois Txai ${ }^{5}$, de Rio Branco, duas professoras, que passaram três meses. Eu não matriculei também, pois morava mais distante, não podia ir estudar. Aí, em 1983, naquele tempo em que nós cortávamos seringa ainda, antes de recebermos o direito de ter nossa terra, delimitarmos nossa terra, precisávamos daquele conhecimento pra negociar com os seringalistas. Aí o nosso cacique, as nossas
5. Txai é uma palavra utilizada pelos Huni Kuĩ para chamar os seus companheiros. Provável etimologia indica que a palavr vem de "txãi", cunhado.
EM TESE
BELO HORIZONTE
v. 22
N. 2
MAIO-AGO. 2016
MANA; SALES; FERREIRA; LIMA; SOUZA. Reflexões sobre a educação [...] P. 282-291 
lideranças, se reuniram e conseguiram conversar sobre esse trabalho, para ter um professor na nossa terra. Nossa liderança conseguiu pra nós, conseguiram com a CPI (Comissão Pró-Índio). A gente fez os projetos, com a força da nossa liderança. Aí a nossa liderança nos convidou, quando chegou o tempo, chegou o projeto para ir fazer um curso. Naquele tempo era um curso de monitores de educação. Aí o nosso cacique nos reuniu, aqueles que sabiam escrever um pouco, umas palavras, e juntamos lá a nossa aldeia, nos reunimos. Nosso cacique passou pra nós que a gente tinha que ir lá na cidade passar um tempo, estudar, aprender alguma coisa, para quando voltar, ensinar para o nosso povo. Aí nós escolhemos então onze jovens. Nós fomos pra cidade de Rio Branco. Passamos lá três meses, aprendemos português e matemática. Aprendemos a fazer conta, soma e subtração, multiplicação e divisão, e português também, aprendemos a escrever algumas frases, pequenas histórias. Daí que voltamos para a aldeia, para a terra indígena. E quando retornamos, levamos o material e iniciamos a trabalhar, a trabalhar o que nós aprendemos, matemática e português primeiro. Naquele tempo a Secretaria (de Educação) não tinha reconhecimento (dos professores indígenas). Nós trabalhamos sem ganhar nada. Eu mesmo cortava seringa por dois dias, depois ficava dois dias na escola, na prática, junto com a comunidade. Iniciamos em 1983. Em 1989 conseguimos um contrato da Secretaria e recebemos algumas bolsas da CPI.
Aí continuamos nesse trabalho, a cada ano, sair da aldeia para a cidade, para formação com o CPI, a cada ano, a cada curso. Passamos 45 dias, dois meses, até que formamos em 2000, conseguimos o magistério. Estudamos muito tempo mesmo. Em 2007 fiz inscrição para matricular na universidade, em Cruzeiro do Sul. Consegui a inscrição e consegui essa formação, e no final recebi um bom ponto. Durante esse trabalho que eu vinha fazendo, eu alfabetizei muitos parentes. Agora eles são professores, agentes de saúde, agentes agroflorestais, lideranças. Então eu estou me sentindo feliz. E atualmente eu estou trabalhando na parte da coordenação, para ajudar o professor, que é o que precisamos conseguir, para nós continuarmos a melhorar. Sobre esse evento, esse encontro, estou achando muito importante. Já aprendemos muito com o $\mathrm{Nawa}^{6}$, esse conhecimento do Nawa que é um conhecimento que tem que trazer também, é muito importante. Mas já estamos trabalhando com a língua escrita, e temos que continuar e valorizar a nossa cultura e a escrita, para registrar o trabalho, a cultura, para escrever e ensinar nossos alunos. É muito importante. O nosso professor, o Mana, ele escreveu mais conhecimentos também sobre a nossa gramática, trabalha também na produção de livro, produzindo as coisas porque não tem ninguém que produz o livro pra gente trabalhar na nossa escola. Do Nawa tem o ensino fundamental, o ensino médio e até superior. Nós também temos que continuar o nosso trabalho, continuar a 
reunir. Como o Mana falou, em cada terra indígena vai ter um núcleo, um centro pra nós discutirmos sobre isso que estamos discutindo, a educação Huni Kuĩ. Os Nawa ensinam mais a cultura deles, e temos que pensar também na nossa cultura. Temos que valorizar essas culturas, tanto a do Nawa quanto a do Huni Kuĩ, porque nós estamos também imersos nessa sociedade.

JOSÉ BENEDITO FERREIRA, PROFESSOR E LIDERANÇA DA ALDEIA ÁGUA VIVA, FAZ UMA REFLEXÃO SOBRE O PRESENTE DA EDUCA ÇÃO HUNI KUĨ.

A educação escolar Huni Kuĩ a gente teve, na verdade, uma iniciativa ao longo dos tempos, discutindo, pensando uma visão que antes era a da educação escolar indígena diferenciada. E, como professores e como pensadores, pensamos aonde estava essa especificidade. E a gente pensou como professor Huni Kuĩ que a educação e a escola tinham que ser voltados para a população de povos indígenas de cada povo, de cada etnia. E começamos a pensar, sentar, discutir. Isso veio ao longo do tempo da formação dos professores, da formação do doutor Joaquim Mana. Pensamos juntos, porque a gente estava vendo que o nosso povo estava em três diferentes graus de conhecimento, do conhecimento do povo Huni Kuĩ. E a gente vê que cada região, cada terra indígena, tem a sua organização diferente. Tem povo Huni Kuĩ que está mais próximo do município, da cidade. E outros estão na cabeceira do rio, e permaneceram com sua própria língua, sua própria cultura. Esses que estão mais próximos do município, na verdade ali a cultura foi engolida pelo conhecimento da língua portuguesa. E isso pra nós, a preocupação que nós trouxemos, é de incentivar, valorizar e buscar o nosso conhecimento pra que futuramente os nossos jovens não venham a perder esse conhecimento que nós temos. Mas a gente vê que atualmente a gente está

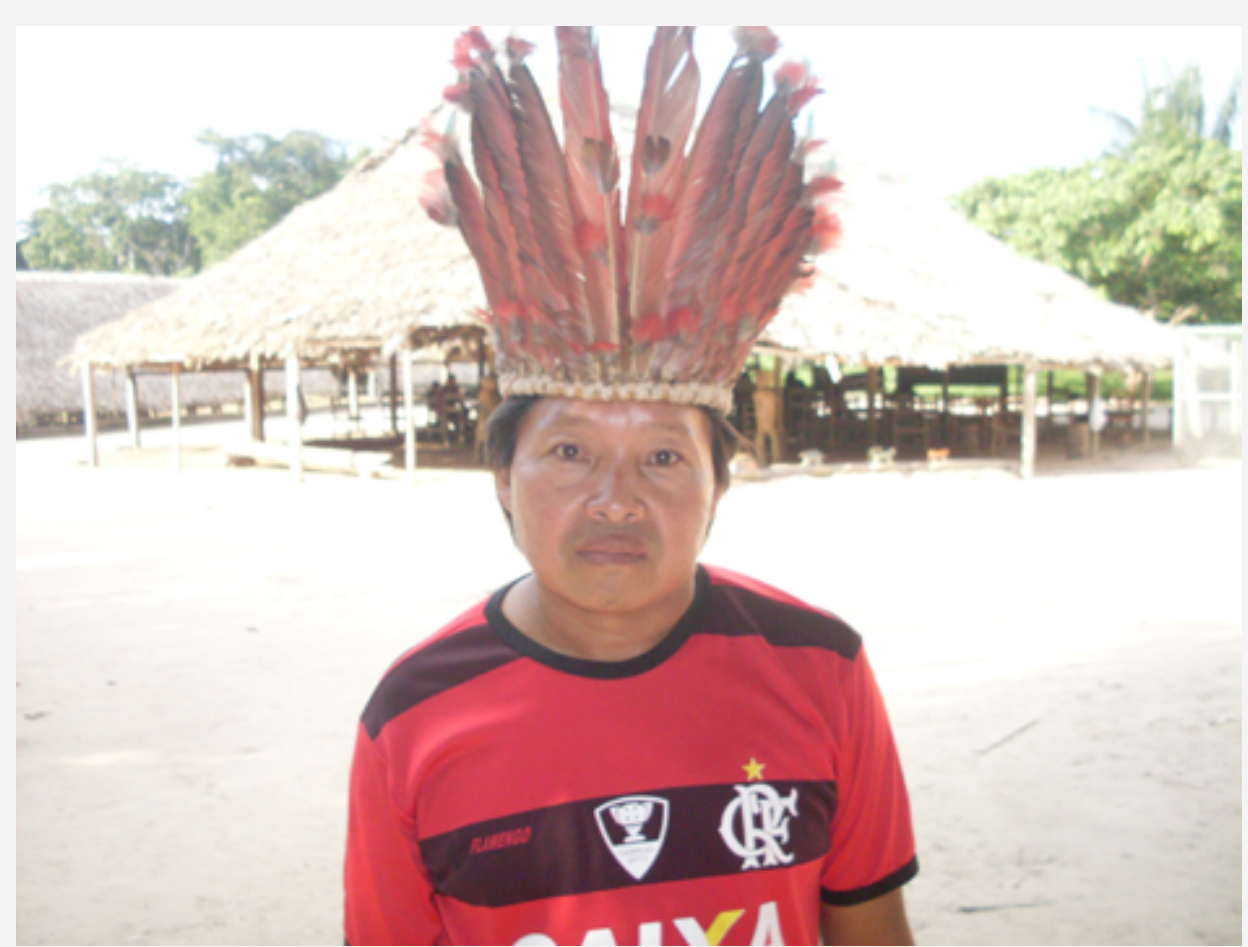

JOSÉ BENEDITO FERREIRA
EM TESE
BELO HORIZONTE
v. 22
N. 2
MAIO-AGO. 2016

MANA; SALES; FERREIRA; LIMA; SOUZA. Reflexões sobre a educação [. . . ]

282-291 
prejudicado. Mas não que estamos prejudicados e acabou. Nós temos uma perspectiva nossa, de a gente buscar essas pessoas e fazer entender que nossa cultura Huni Kuĩ, que ainda está viva, precisa ser valorizada, precisa ser mantida, precisa ser fortalecida em todos os conhecimentos. É pra isso que hoje nós estamos nesse curso de política linguística. No início, na abertura do curso, a gente viu que tem povo Huni Kuĩ que nunca tinha visto um Katxanawa que é a festa da fertilidade dos legumes. Nós estamos aqui fazendo um plano decenal. A gente não tem como, na verdade, viver como no passado, parar de comer sal, viver nu. Isso não tem como. Mas a gente tem como buscar, retomar um pouco a nossa língua, a nossa vivência cultural, a nossa organização interna, de pai pra filho, de filho pra pai, do respeito dos clãs. Enfim, hoje, muitos povos, muitas pessoas não conhecem qual é o respeito da família materna, qual o respeito da família paterna, como se chamam as pessoas, enfim, pelo nome. Então isso ainda está dentro de muitas terras indígenas que estão mais próximas do município, que perderam esse costume. Então a tendência nossa é buscar isso e levar pras pessoas. Dentro da leitura hoje, estamos vendo que existem três graus de conhecimento: tem pessoas que estão começando agora, a falar, a ler, né, tentando valorizar. Tem outros que já estão mais ou menos, pelo meio do caminho, tentando buscar, estão lendo, escrevendo, fazendo. Tem outros que, na verdade, permaneceram. Estamos tendo esse curso como uma troca de experiências. Porque a gente já tem um pouco de conhecimento na questão da língua portuguesa. E agora precisamos trazer o nosso lado, equilibrar o conhecimento, o quanto do nosso e o quanto da língua portuguesa. Por que nós estamos tentando manter a nossa língua, o nosso conhecimento? Isso é a nossa cultura. E o conhecimento da língua portuguesa é porque a gente tem que se comunicar. A gente não tem como parar mais, a gente está no meio da sociedade não indígena, a gente está no meio da sociedade envolvente. Nisso a gente tem que se comunicar, nós temos que defender os nossos direitos, nós temos que informar o que nós queremos e o que nós não queremos, nós temos que informar o que é bom pra nós e o que não é bom pra nós, para os povos indígenas, para a terra indígena, para a sociedade indígena. É preciso dialogar com o indígena e com o não indígena. A sociedade precisa nos entender e nós precisamos conhecer esse mundo que está aí fora, que na verdade é um mundo burocrático, das leis, que a gente tem que andar conhecendo a lei, como viver e como fazer. Isso é o nosso objetivo de estar aqui, nesse curso, de conhecermos ambos os conhecimentos e fortalecer a nossa cultura, porque se a gente não fizer isso, daqui dez ou vinte anos, a nossa língua pode ser extinta, nossa cultura pode ser extinta, e muito do conhecimento dos velhos ficará só na história. Então isso é mais para fortalecer, para trazer os nossos jovens, formar os professores, incentivar 
7. Construção de madeira e palha onde ocorrem diversas atividades comunitárias da aldeia. os professores. Cada professor que está aqui participando desse curso, que chegue na sua comunidade, na sua terra indígena, e leve para outros professores e para os seus alunos, e que incentive os idosos que conhecem a cultura para que venham para o Kupixau ${ }^{7}$, para a contação de histórias, que venham dançar o seu Katxanawa. Incentivar e levar isso para as terras indígenas. Isso é nosso objetivo.

$$
* * *
$$

GILSON DE LIMA KAXINAWA (SIÃ RUA BAKE), PROFESSOR DA ALDEIA MIBÃYA E CINEASTA, FALA DAS PERSPECTIVAS PARA O FUTURO DA EDUCAÇÃO ESCOLAR.

A perspectiva que a gente tem do futuro é poder melhorar o quadro de educação, principalmente na escrita. Mas não só na escrita. Nós temos vários territótios, e cada território tem sua realidade diferente. Em muitas aldeias, muitas terras indígenas, já não se fala mais. Só se tem o português, e não o Hãtxa Kuĩ. Então com esse evento, com esse trabalho que a gente está fazendo, queremos mudar essa quadro através da escrita, através da escola, através dos professores, porque, hoje em dia, a comunidade aposta muito no professor. O professor é o educador, o ensinador, é o exemplo da comunidade. Esse trabalho que estamos fazendo é não só mudar a forma de ver, mas também de praticar nossas tradições, resgatar toda nossa tradição que a gente já vem perdendo. Hoje em dia a gente não vive só, só nós. A gente vive numa sociedade de muitas coisas, e isso influencia muito como a gente vive, como a gente trabalha, como pensa. Com esse trabalho então, é para ver, sentar, discutir, pensar no que a gente está fazendo. Quais são os resultados positivos? Quais são os resultados negativos que se está tendo dentro da comunidade, da terra indígena, dentro do povo? Então, esse trabalho é mais para refletir isso e nós mesmos começarmos a trabalhar em cima disso: isso aqui não está bom, vamos ver como a gente

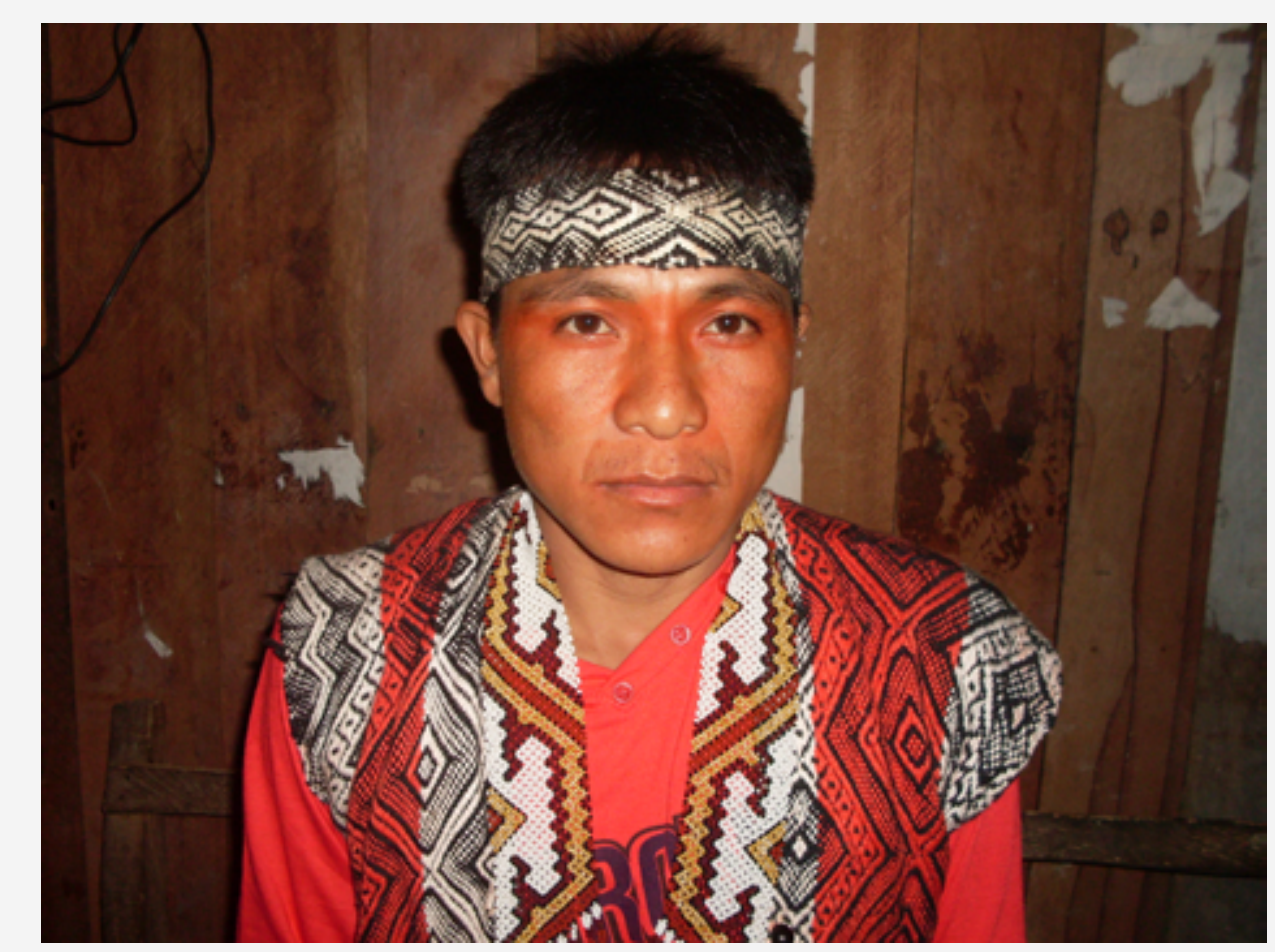

GILSON DE LIMA
EM TESE
BELO HORIZONTE
v. 22
N. 2
MAIO-AGO. 2016

MANA; SALES; FERREIRA; LIMA; SOUZA. Reflexões sobre a educação [...] P. 282-291 


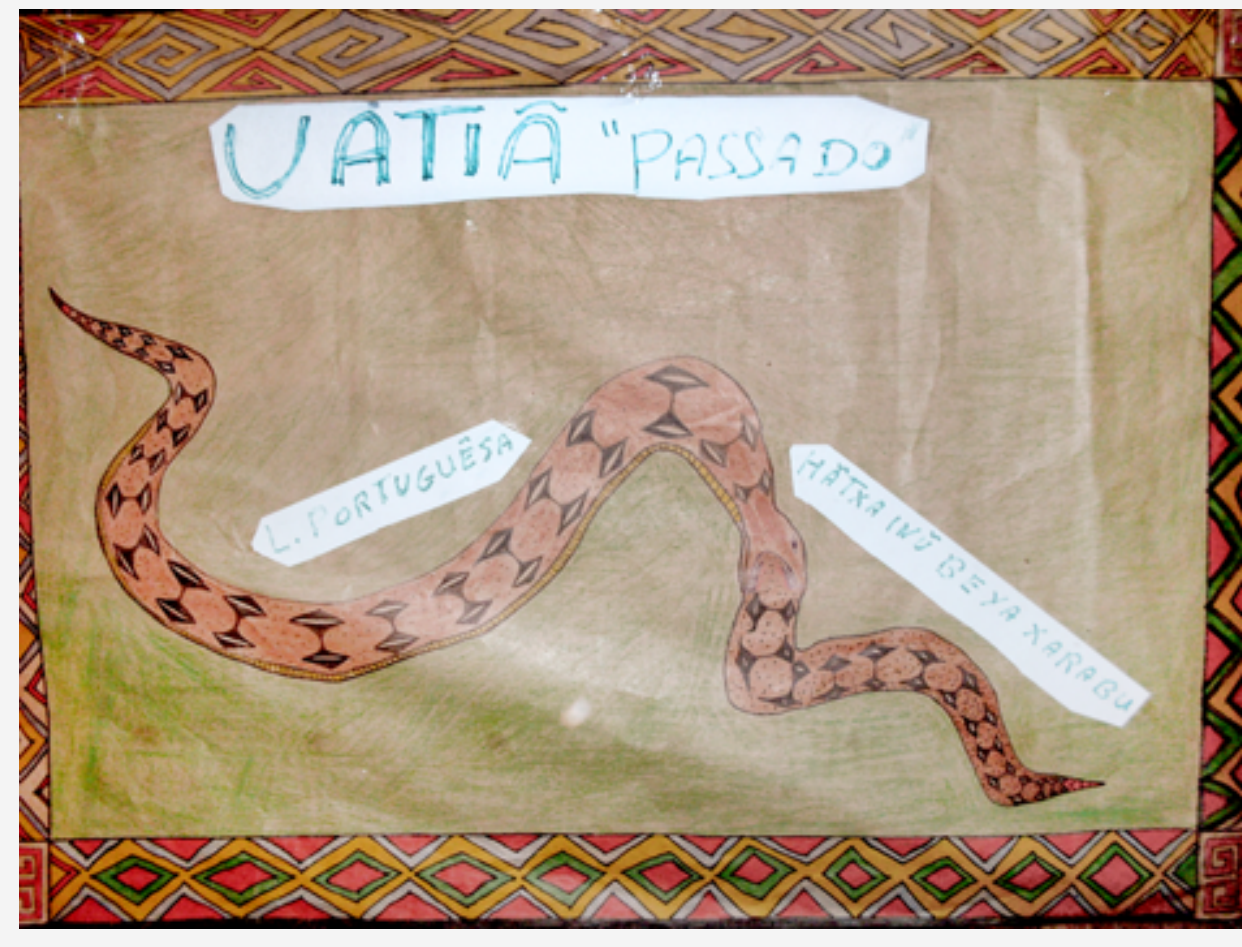

Passado

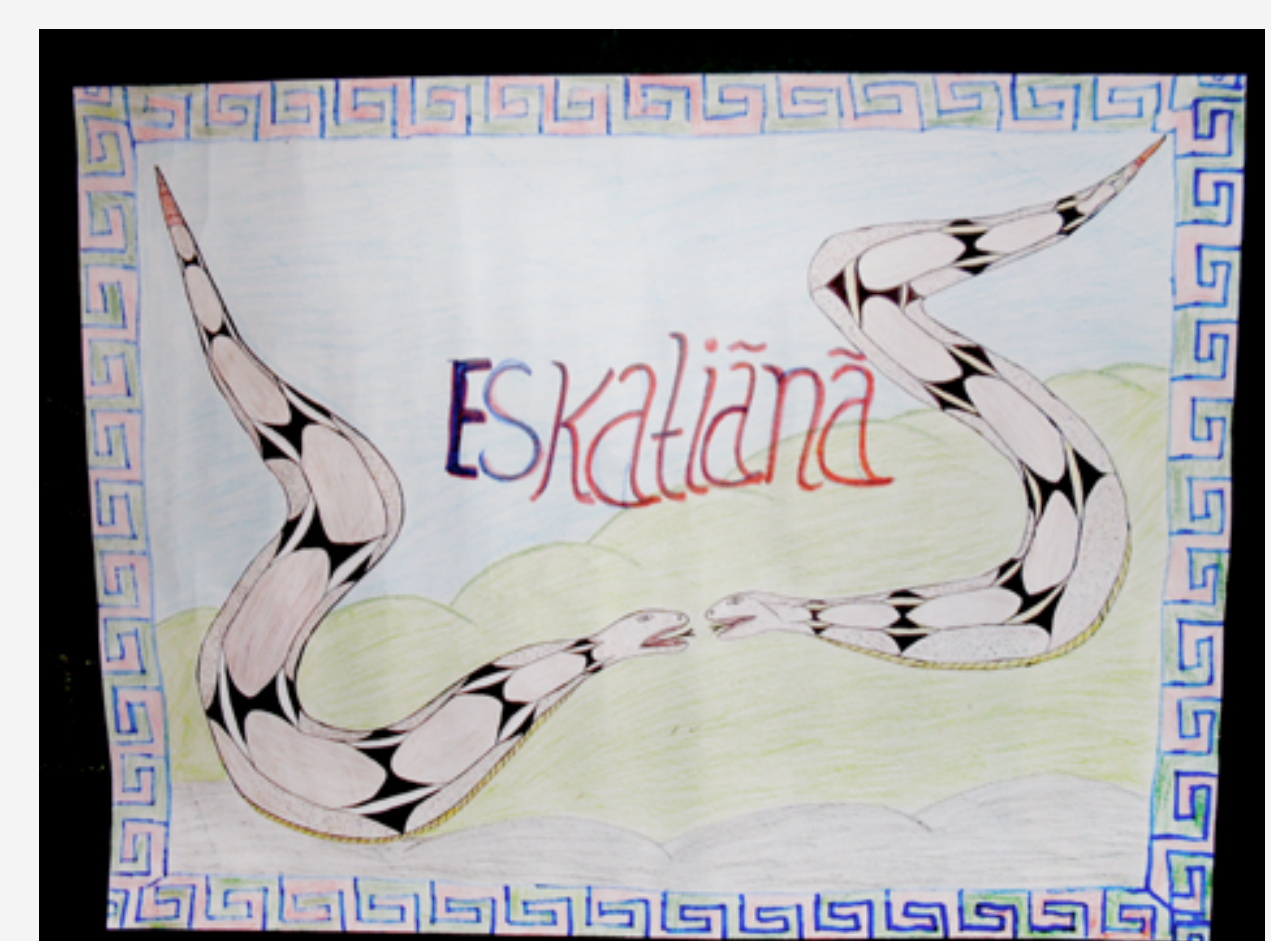

Presente

faz. Isso aqui está legal, vamos trabalhar mais em cima disso, para envolver mais pessoas, mais comunidades, mais terras indígenas. Acho que é só pensamento bom, esse terceiro encontro que está havendo. Esse é o mais importante de todos, pois a maioria das terras indígenas estão aqui reunidas. Eles estão tendo essa oportunidade de ver, de ouvir, de poder se expressar, de poder fazer a troca da experiência, do trabalho, da convivência. Desse ponto em diante, vai mudar a valorização. O que é trabalhar sem ter as ferramentas necessárias para o trabalho? Aqui nós estamos tendo essas ferramenteas para o trabalho. A gente está tendo esse conhecimento, essa informação de onde podemos retirar essas ferramentas. Às vezes a gente fica esperando alguém mandar essa ferramenta, mas não é isso. O trabalho é da tradição, da cultura. Tem tudo ao nosso redor, mas por falta de conhecimento disso, a gente não trabalha em cima disso. Daqui pra frente, estou vendo isso. As pessoas que estão aqui estão vendo nitidamente como é que está acontecendo, qual é o objetivo desse encontro, qual é o objetivo dos líderes que estão aqui e como levar isso para suas comunidades. Por falta de ferramenta

EM TESE BELO HORIZONTE $\quad$ v. $22 \quad$ N. 2 MAIO-AGo. 2016 MANA; SALES; FERREIRA; LIMA; SOUZA. Reflexões sobre a educação [...] P. 282-291


não será mais: estamos construindo livros, vendo de qual forma podemos trabalhar na escola. De agora para trás, só tinha materiais do nawa [branco], então ficava difícil para alguém que não tinha uma organização de trabalho em cima do Hãtxa produzir o seu próprio trabalho. Agora tendo mais livros, fica mais fácil de ler, de fazer as atividades, de fazer um trabalho em cima do livro, em cima do que já foi escrito, ver a realidade daquele outro lugar e fazer a sua realidade. Acho que vai ter mais tempo de ensino em Hãtxa Kuĩ do que as outras matérias que não são do Huni Kuĩ. Então, vai ter livro de História, livro de aprendizado, lilvro de Medicina. Com isso o professor e os alunos vão ter um amplo conhecimento para estar estudando. Eles terão como estudar, como trabalhar em cima daquilo. A produção dos livros é pensando nisso. Como eu falei, cada localidade tem uma realidade diferente, então mesmo que seja uma pessoa com vontade de trabalhar, se não tem os materiais necessários, fica difícil, não tem de onde tirar se o velho já não fala mais, se a família já não fala mais, se ele já não fala mais, fica difícil. Agora, tendo os materiais, al tem tudo. Tem o velho, tem o sábio, tem o pajé, tem o mestre, tudo ali naquele livro. A ideia de produzir mais livros é pensando nisso. Não só pensando nas pessoas que tem essa dificuldade de falar, mas também nas pessoas que são falantes. Os livros levam aos trabalhos, à história de cada região - mesmo sendo Huni Kuĩ há histórias diferentes.
Até agora estamos vendo que, mesmo sendo falantes, a parte escrita, a leitura, lemos muito pouco e escrevemos muito pouco. Escrevemos mais a [língua] do nawa do que a nossa. Mas tendo esse material, eu acredito muito que isso vai mudar.

$* * *$ 